\title{
Study of a Standardized Taurocholate- Lecithin Powder for Preparing the Biorelevant Media FeSSIF and FaSSIF
}

\author{
Bastian Kloefer ${ }^{1,2}$, Peter van Hoogevest ${ }^{1}$, \\ Ruth Moloney ${ }^{1}$, Martin Kuentz ${ }^{2}$, \\ Mathew L.S. Leigh ${ }^{1, *}$, and Jennifer Dressman ${ }^{3}$ \\ ${ }^{1}$ Phares AG, Klünenfeldstrasse 30, CH-4132 Muttenz, Switzerland \\ ${ }^{2}$ University of Applied Sciences Northwestern Switzerland, Institute of Pharma Technology, \\ Gründenstrasse 40, CH-4132 Muttenz, Switzerland \\ ${ }^{3}$ Institute of Pharmaceutical Technology, Johann Wolfgang Goethe University, \\ Frankfurt am Main, Germany
}

\begin{abstract}
The properties of taurocholate-lecithin powder (SIF Powder) and the biorelevant media FeSSIF and FaSSIF prepared from the powder were investigated using various techniques. The powder is stable and shows no change in the physical or chemical characteristics for at least 12 months in the original container stored at $2-8^{\circ} \mathrm{C}$. FeSSIF and FaSSIF were stable with respect to hydrolysis for at least $48 \mathrm{~h}$ at $37^{\circ} \mathrm{C}$. Oxidation in FeSSIF was detected at a very low level and to an even lower extent in FaSSIF. FaSSIF comprises a complex mixture of colloidal aggregates including rod-like, spherical, disc-like mixed micelles and vesicles. Consistent particle size was achieved by equilibrating the medium at room temperature (RT) after preparation. In comparison, FeSSIF only comprises smaller mixed micelles and requires no equilibration. The dissolution rates of three poorly water-soluble model drugs tested in FaSSIF media differing in average particle size controlled at $30 \mathrm{~nm}$ and $50 \mathrm{~nm}$ were not statistically different. However, differences in the average particle size can affect visual clarity: FaSSIF is generally slightly opalescent above an average size of approximately $50 \mathrm{~nm}$ and appears clear below approximately $50 \mathrm{~nm}$. Challenge tests showed that FaSSIF is more susceptible to microbial spoilage than FeSSIF. Reproducible FeSSIF and FaSSIF can be made conveniently from the powder by employing standard preparation methods at RT.
\end{abstract}

\section{INTRODUCTION}

imulated small intestinal biorelevant media are
increasingly seen as a helpful tool to assess the
dissolution and solubility of drugs. Fasted-state simulated intestinal fluids (FaSSIF) and fed-state simulated intestinal fluids (FeSSIF) were introduced by Prof. Jennifer Dressman in 1998 (1) and contain the natural solubilizers bile salt and lecithin in amounts similar to intestinal fluids. Since their introduction, numerous articles have correlated the in vitro dissolution behavior of poorly water-soluble drugs in biorelevant media to in vivo oral absorption (for recent reviews of IVIVR, see 2,3). Biorelevant media are also of interest to anticipate potential food effects and to model drug-absorption processes (4).

Conventional dissolution media for poorly soluble drugs contain synthetic surfactants, such as sodium dodecyl sulfate, which form micelles. In contrast, FeSSIF and FaSSIF contain natural surfactants that form more complex lipid aggregates. Methods of preparing biorelevant media involve emulsification in a chlorinated solvent (5) or sequential additions (6). Regardless of the method used, for reproducibility, the quality and specification of the taurocholate and lecithin must be taken into

${ }^{*}$ Corresponding author. account (7). Recently, modified compositions for FeSSIF and FaSSIF have been proposed (8).

Phares introduced SIF Powder (www.ePhares.com) consisting of high-specification taurocholate and lecithin to facilitate the rapid and standardized preparation of either FaSSIF or FeSSIF (9). In a recent publication (10), the performance of FaSSIF prepared by the emulsion method, "instant" FeSSIF and FaSSIF prepared by a solvent elimination method, and commercially available SIF Powder were compared. It was concluded that the powder provides an accurate, reproducible, and efficient way of preparing ready-to-use biorelevant media.

This paper characterizes SIF Powder and examines how FeSSIF and FaSSIF media can be reproducibly prepared from the powder. The physical, chemical, and microbiological stability of the media were investigated along with the dissolution of three poorly water-soluble drugs in FaSSIF. The results of the structures observed in both biorelevant media are discussed in the context of the physicochemical characteristics of the lecithin and taurocholate.

\section{MATERIALS AND METHODS}

Ketoconazole was obtained from Piramal Healthcare Limited (Mumbai, India); dipyridamole and phenytoin were from Sigma Aldrich Chemie GmbH (Buchs, Switzerland). All other chemicals conform to at least analytical quality. 


\section{Determination of Hygroscopicity}

Samples of the powder were exposed to a temperature of $25^{\circ} \mathrm{C}$ and $60 \% \mathrm{RH}$ using a saturated salt solution. The change in weight after exposure was followed with time.

\section{Phospholipid Content of the Powder and in FeSSIF and FaSSIF}

Test material (200-1000 mg) and $10 \mathrm{mg}$ of internal standard TPP (triphenylphosphate) were dissolved in $1 \mathrm{~mL} \mathrm{CDCl}{ }_{3}, 2 \mathrm{~mL}$ methanol, and $2 \mathrm{~mL}$ aqueous Cs/EDTA solution (0.2 M, pH 7.5). After the mixture was shaken for $15 \mathrm{~min}$, the two phases were centrifuged and measured separately. A high-field NMR spectrometer (Bruker Avance $300 \mathrm{MHz}$ ) was used to measure and integrate signals relating to lecithin, lysolecithin, and TPP.The limit of quantification and detection for ${ }^{31} \mathrm{P}-\mathrm{NMR}$ was estimated to be $0.16 \mathrm{~mol} \%$ when measuring phospholipid content in either the organic or aqueous phase.

\section{Taurocholate Content of the Powder}

The taurocholate content of the powder was determined by the HPLC method described by Rossi et al. (11).

\section{Water Content}

The water content of the powder was determined by loss on drying using a Sartorius MA-45 moisture meter.

\section{Measurement of Degree of Oxidation of Phospholipid (UV)}

The initial formation of peroxides (double-bond conjugation) in the unsaturated fatty acid residue of the phospholipid molecule was measured by UV.The spectra show maxima around $230 \mathrm{~nm}$ and between 270 and 280 $\mathrm{nm}$ (12). Samples of powder were dissolved and diluted with methanol and scanned from 190 to $400 \mathrm{~nm}$ using a 1-cm path length, quartz cuvette and a Perkin Elmer Lambda 15 spectrophotometer. The level of oxidation expressed as mole percent peroxide per total phospholipid is derived from the baseline corrected absorbance and the molar extinction of oxidized fatty acids of $27,000 \mathrm{M}^{-1} \mathrm{~cm}^{-1}$ at $234 \mathrm{~nm}$ (13). Similarly, oxidation in FaSSIF or FeSSIF was measured by diluting samples with methanol in a 1-cm cuvette. The results are the average of three UV measurements. The standard deviation in the observed extinction range was $2 \%$.

\section{Measurement of Degree of Oxidation of Phospholipid (Malondialdehydes)}

Malondialdehydes (MDA) are formed when peroxides of the phospholipid fatty acid are further oxidized (12) and can be detected by UV.The Malondialdehyde Assay kit (product NWK-MDA01, Northwest Life Science Specialties, LLC, USA) was used based on the reaction of MDA with thiobarbituric acid (TBA), which forms a strongly absorbing adduct at $532 \mathrm{~nm}$. The assay was calibrated using known MDA concentrations. It is assumed that one mole of MDA represents one mole of oxidized phospholipid and the result expressed as mole percent peroxide per total phospholipid. The results are the average of three UV measurements. The standard deviation in the observed extinction range was $2 \%$.

\section{Determination of Particle Size (PCS)}

The average particle size (expressed as $Z_{a v}$ ) and distribution (expressed as polydispersity index) in FeSSIF and FaSSIF were determined by PCS (photon correlation spectroscopy). Measurements were performed on undiluted, unfiltered samples in Plastibrand 2.5-mL macro PS cuvettes using a Zetasizer ZS (nano series, Malvern Instruments) with noninvasive backscattering at an angle of $173^{\circ}$. Measurements were performed in triplicate at the same temperature as the test medium. The standard deviation of the measured $Z_{a v}$ was $2 \%$.

\section{Cryogenic Transmission Electron Microscopy}

Five microliters of each sample was applied to Quantifoil (Germany) copper grids, which were subsequently mounted on a plunger, blotted, and vitrified in liquid ethane at $-180^{\circ} \mathrm{C}$. The samples were immediately transferred in a cryo-holder to the cryo-transmission electron microscope (Philips CM120). Images were recorded with a FastScan-F114 CCD Camera (TVIPS GmbH, Germany). To minimize noise interference, five images were recorded and averaged to a single image.

\section{Microbiological Challenge Test}

The Microbial Challenge Test (Eur. Pharm. (14)) was applied to assess the susceptibility of sterile filtered FeSSIF and FaSSIF to grow Staphylococcus aureus, Pseudomonas aeruginosa, Aspergillus niger, and Candida albicans.

\section{Dissolution Testing}

Dissolution of three drugs in FaSSIF was performed in triplicate at $37^{\circ} \mathrm{C}$ using USP Apparatus 2 (PTW S300, PharmaTest) with the paddle rotating at $50 \mathrm{rpm}$ with $500 \mathrm{~mL}$ in $1-\mathrm{L}$ vessels. The concentration of each drug was $20 \mu \mathrm{g} / \mathrm{mL}$ ketoconazole, $15 \mu \mathrm{g} / \mathrm{mL}$ dipyridamole, and $20 \mu \mathrm{g} / \mathrm{mL}$ phenytoin. Samples were withdrawn at predetermined intervals, passed through a $0.45-\mu \mathrm{m}$ pore size filter, and assayed for drug content using an in-house HPLC method. The standard deviation and the similarity factor $f_{2}$ were calculated (15).

\section{Production of Powder}

SIF Powder was manufactured under strictly controlled and validated conditions. Premium grade soybean lecithin and sodium taurocholate were complexed in a 4:1 molar ratio using a proprietary process (9). Fifty-six grams of the powder was filled in a glass container with a recloseable screw-top cap.

\section{Preparation of FeSSIF from the Powder}

FeSSIF was prepared at RT by dissolving $20.2 \mathrm{~g}$ of $\mathrm{NaOH}$ (pellets), $43.25 \mathrm{~g}$ of glacial acetic acid, and $59.37 \mathrm{~g}$ of $\mathrm{NaCl}$ 


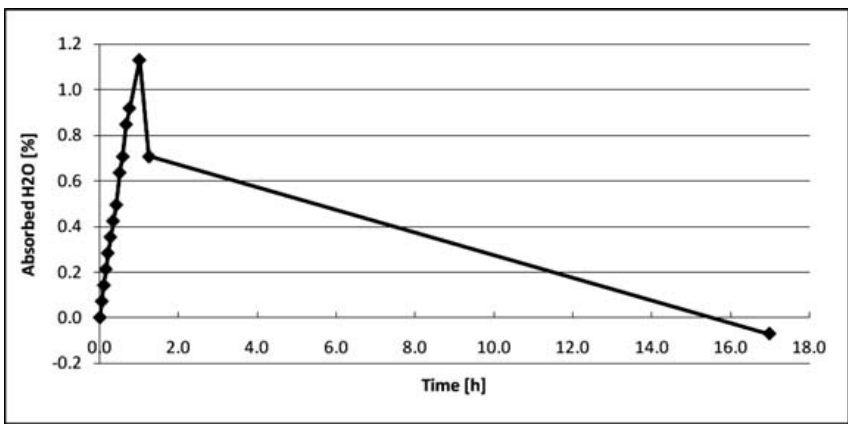

Figure 1. Hygroscopicity of the Powder at $25^{\circ} \mathrm{C}$ at $60 \%$ RH and influence of desiccant; sachet was added at time point 1.

in $5 \mathrm{~L}$ of purified water. The $\mathrm{pH}$ was adjusted to 5.0 using either $1 \mathrm{~N} \mathrm{NaOH}$ or $1 \mathrm{~N} \mathrm{HCl}$ (blank FeSSIF buffer). In a 1-L volumetric flask, $11.2 \mathrm{~g}$ of powder was dissolved in approximately $500 \mathrm{~mL}$ of the blank FeSSIF buffer to produce a clear solution and made up to volume. FeSSIF was stored at RT and used within $48 \mathrm{~h}$ unless otherwise stated.

\section{Preparation of FaSSIF from the Powder}

FaSSIF was prepared at RT by dissolving $1.74 \mathrm{~g}$ of $\mathrm{NaOH}$ (pellets), $17.19 \mathrm{~g}$ of anhydrous $\mathrm{NaH}_{2} \mathrm{PO}_{4}$, and $30.93 \mathrm{~g}$ of $\mathrm{NaCl}$ in $5 \mathrm{~L}$ of purified water (blank FaSSIF buffer). The $\mathrm{pH}$ was adjusted to 6.5 using either $1 \mathrm{~N} \mathrm{NaOH}$ or $1 \mathrm{~N} \mathrm{HCl}$. In a 1-L volumetric flask, $2.24 \mathrm{~g}$ of powder was dissolved in approximately $500 \mathrm{~mL}$ of the blank FaSSIF buffer and made up to volume. FaSSIF was stored at RT and used within $48 \mathrm{~h}$ at RT or within $24 \mathrm{~h}$ at $37^{\circ} \mathrm{C}$ unless otherwise stated. Further experimental details are described in the Results section.

\section{RESULTS}

Powder Studies

Hygroscopicity

The water uptake after exposure at $25^{\circ} \mathrm{C} / 60 \%$ RH was examined. It can be seen from Figure 1 that the powder absorbs about $1 \%$ water within one hour. Therefore, to prevent moisture uptake, a sachet containing a waterabsorbing molecular sieve capable of absorbing $1.2 \mathrm{~g}$ of water was packed with the powder in the container.

\section{Desiccant Sachet}

Adding the desiccant to powder that was exposed for one hour at $25^{\circ} \mathrm{C}$ and $60 \% \mathrm{RH}$ atmosphere decreased the weight and corresponding water content rapidly to at least the same level as before exposure (Figure 1).

\section{Physical Stability of the Powder}

On visual inspection, the powder remained free-flowing after storage for twelve months at $2-8{ }^{\circ} \mathrm{C}, \mathrm{RT}$, and $40^{\circ} \mathrm{C}$ in closed containers along with the desiccant. The time required to hydrate the powder to produce either FaSSIF or FeSSIF did not change and was less than five minutes in all cases. The moisture content of the powder was unchanged in the unopened containers, which were stored under the recommended conditions demonstrating the integrity of the primary packaging.

\section{Chemical Stability of the Powder}

The complex comprises lecithin, which can hydrolyze to lysolecithin under certain conditions (16). The chemical stability of the product in an unopened container stored for one year at $2-8^{\circ} \mathrm{C}, \mathrm{RT}$, and $40^{\circ} \mathrm{C}$ is provided in Table 1 .

No increase in lysolecithin was detected under the conditions tested, confirming that the powder is chemically stable under the conditions tested.

\section{Oxidative Stability of the Powder}

Powder stored for twelve months at $2-8{ }^{\circ} \mathrm{C}, \mathrm{RT}$, and $40^{\circ} \mathrm{C}$ in closed vials shows a level of oxidation below $0.009 \%$ (UV) and below $0.006 \%$ (malondialdehyde). Considering this very low level of oxidation, storage of the powder under protective gas was considered unnecessary.

The chemical and physical stability data of the powder in sealed containers with a desiccant justifies a shelf life of at least 12 months at $2-8{ }^{\circ} \mathrm{C}$.

Investigating FeSSIF and FaSSIF Produced from the Powder

The physicochemical stability and reproducibility of FeSSIF and FaSSIF produced from the powder were further examined. These properties are investigated in the following sections. The mixed micelle composition prepared from the powder is identical to that described by Marques (5).

\section{Chemical Stability of FeSSIF and FaSSIF}

In addition to taurocholate, FeSSIF and FaSSIF contain lecithin dispersed in an aqueous environment at $\mathrm{pH} 5$ and 6.5 , respectively. In water, lecithin may hydrolyze and oxidize in a manner similar to liposomes (12). The formation of lysolecithin in both media assessed by ${ }^{31} \mathrm{P}-\mathrm{NMR}$ was below the detection limit of $0.16 \mathrm{~mol} \%$ after $48 \mathrm{~h}$ at $37^{\circ} \mathrm{C}$.

Table 1. Sodium Taurocholate and Lecithin Content of the Powder

\begin{tabular}{lccc}
\hline $\begin{array}{l}\text { Time } \\
\text { Point }\end{array}$ & $\begin{array}{c}\text { Temperature } \\
\left({ }^{\circ} \mathrm{C}\right)\end{array}$ & $\begin{array}{c}\text { Lecithin Content } \\
\text { (\% of initial content) }\end{array}$ & $\begin{array}{c}\text { Sodium Taurocholate } \\
\text { Content } \\
\text { (\% of initial content) }\end{array}$ \\
\hline$T_{0}$ & 100 & 100 \\
\hline$T_{6-\text { month }}$ & $2-8$ & 98.4 & 102.1 \\
\cline { 2 - 4 } & RT & 101.2 & 100.7 \\
\cline { 2 - 4 } & 40 & 100.8 & 99.9 \\
\hline$T_{1-\text { year }}$ & $2-8$ & 100.4 & 98.9 \\
\cline { 2 - 4 } & RT & 100 & 96.7 \\
\cline { 2 - 4 } & 40 & 101.6 & 94.9 \\
\hline
\end{tabular}




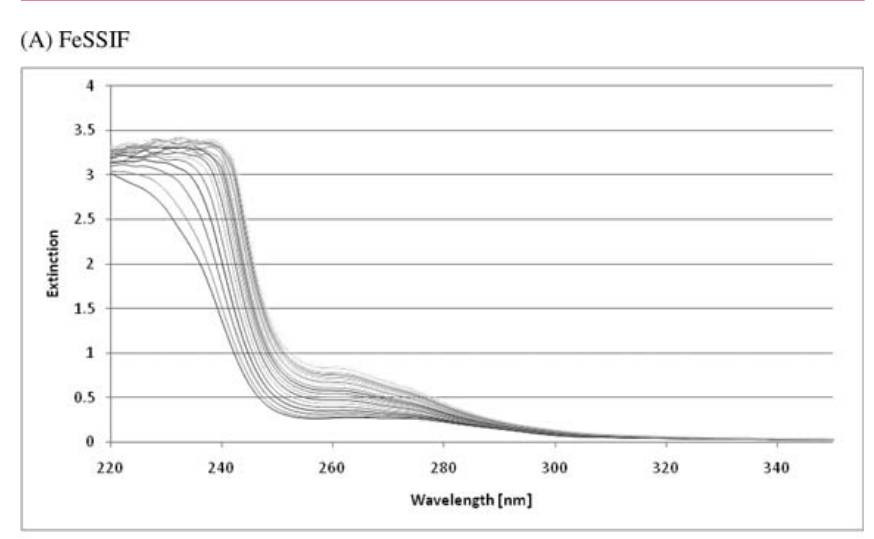

(B) FaSSIF

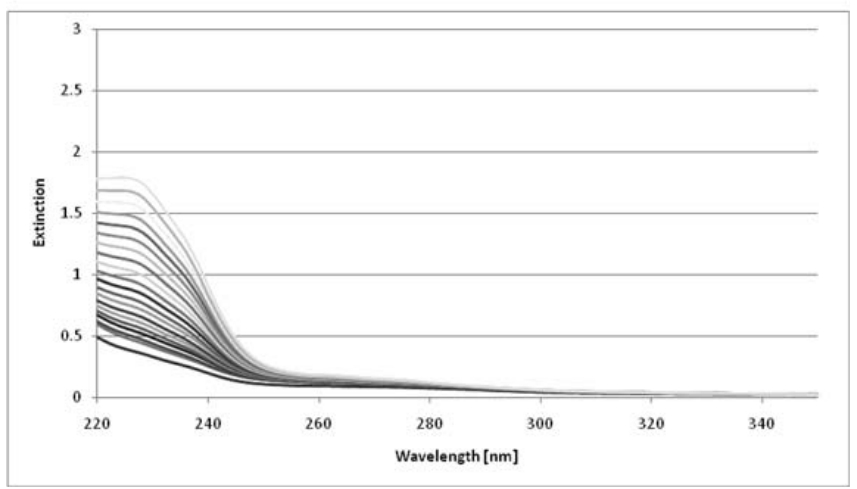

Figure 2. Oxidation for $24 \mathrm{~h}$ at RT of undiluted (A) FeSSIF and (B) FaSSIF measured by UV spectroscopy at hourly intervals.

Oxidative Stability of FeSSIF and FaSSIF

To assess phospholipid oxidation in FeSSIF and FaSSIF, the UV spectra of undiluted samples of the media were measured (Figure 2).

FeSSIF (undiluted) shows a significant amount of UV self-absorbance below $300 \mathrm{~nm}$. The UV self-absorbance of
FaSSIF was lower, probably because of the five-fold lower cholate/phospholipid concentration. After storage for $24 \mathrm{~h}$ at RT, FeSSIF exhibited an additional gradual increase in absorbance at approximately $230 \mathrm{~nm}$ and $270-280 \mathrm{~nm}$, due to phospholipid oxidation. At about $230 \mathrm{~nm}$, an accurate determination of the UV extinction of FeSSIF with $1-\mathrm{cm}$ cuvette was not possible because the values were too high. To quantitatively determine the level of oxidation by UV, the medium was diluted with methanol. Based on the molar extinction coefficient of peroxidized fatty acids at $27,000 \mathrm{M}^{-1} \mathrm{~cm}^{-1}$, the highest level of oxidation detectable after $24 \mathrm{~h}$ for FeSSIF was around $0.01 \mathrm{~mol} \%$ and for FeSSIF about 0.003 mol\% total phospholipid.

\section{Physical Characterization of FaSSIF and FeSSIF \\ Electron Micrographs}

Cryogenic transmission electron micrographs of FaSSIF at RT reveal the presence of several types of colloidal structures (Figure 3 right).

In addition to spherical mixed micelles, the circularshaped gray areas are interpreted as disk micelles, while the irregularly shaped micelles are interpreted as bilayer micelles. Rod-like aggregates, which could be disk or bilayer micelles, can also be observed along with some vesicular structures (liposomes) (Figure 3 middle). For comparison, a cryo-transmission electron micrograph of FeSSIF is provided in Figure 3 (left) where only smaller, mixed micelles are observed.

\section{FaSSIF Particle Size}

The particle size was approximately $20 \mathrm{~nm}$ immediately after preparation. The initial value depends on the time between the addition of powder to the aqueous medium and the particle size measurement. Based on PCS measurements, the structures in FaSSIF require approximately two hours to reach a relatively constant $Z_{\mathrm{av}}$ (between about 30 and $70 \mathrm{~nm}$ ). The particle sizes of FaSSIF prepared

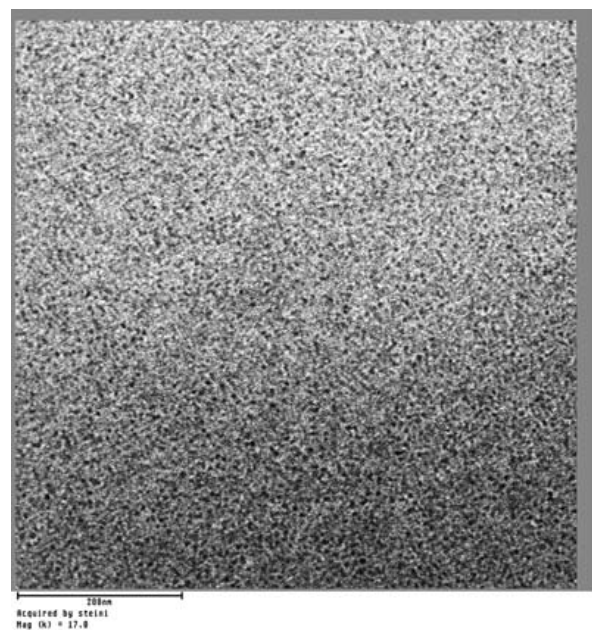

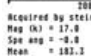

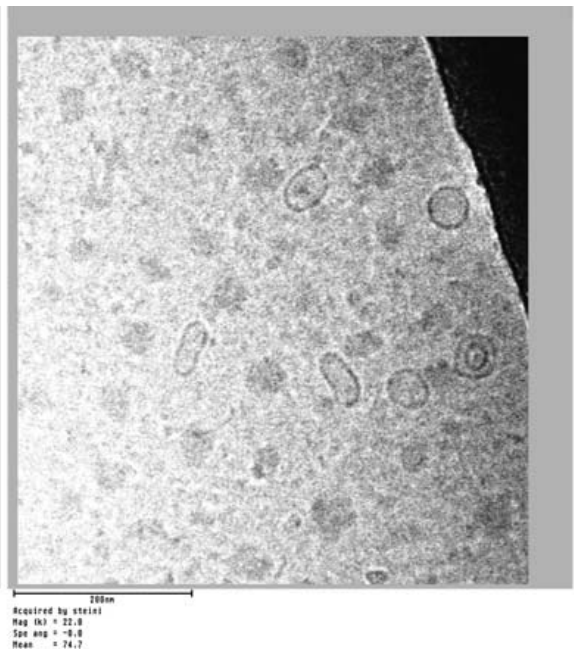

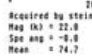

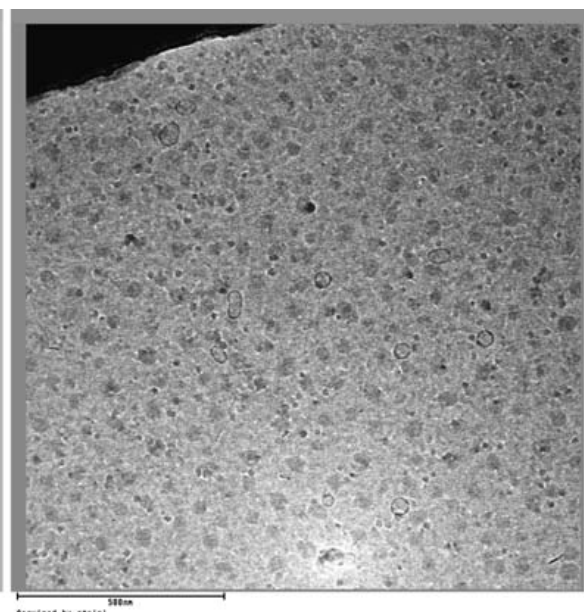

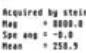

Figure 3. Cryo-transmission electron micrographs of FeSSIF (left panel) and FaSSIF (middle and right panel). 
Table 2. Inter- and Intrabatch Reproducibility of Particle Size in FaSSIF at RT

\begin{tabular}{lcc}
\hline Batch No. & $\begin{array}{c}\boldsymbol{Z}_{\text {av }}[\mathbf{n m}] \pm \text { SD } \\
(\boldsymbol{n}=\mathbf{3}) \text { after } \mathbf{2} \mathbf{h}\end{array}$ & $\begin{array}{c}\boldsymbol{Z}_{\text {av }}[\mathbf{n m}] \pm \text { SD } \\
(\boldsymbol{n}=\mathbf{3}) \text { after 48 } \mathbf{h}\end{array}$ \\
\hline 2909 L11 & $49.2 \pm 0.4$ & $52.5 \pm 0.5$ \\
\hline 2909 L12 & $48.7 \pm 1.2$ & $51.4 \pm 1.0$ \\
\hline PHA S 0903 020 & $48.7 \pm 0.3$ & $49.9 \pm 0.3$ \\
\hline
\end{tabular}

with the same and with different batches of powder using the method described (see Method section) are provided in Table 2. The particles were measured $2 \mathrm{~h}$ and $48 \mathrm{~h}$ after addition of the powder to the aqueous medium.

\section{Influence of Storage Temperature on Particle Size}

FaSSIF was prepared and equilibrated for $2 \mathrm{~h}$ at RT. The medium was subsequently (1) refrigerated, (2) kept at RT, or (3) heated to $37^{\circ} \mathrm{C}$. The storage temperature after preparation influenced the average particle size and appearance of the medium to some extent (Figure 4).

The figure shows that equilibration and storage at $2-8{ }^{\circ} \mathrm{C}$ increased the particle size to $62 \mathrm{~nm}$. At RT and at $37^{\circ} \mathrm{C}$, the size remained at approximately $50 \mathrm{~nm}$. This effect was consistent throughout several experiments performed on FaSSIF prepared from at least three batches of SIF Powder. Since refrigeration could be desirable for slowing microbial growth, it was determined if the original particle size of a sample could be restored after warming to RT. However, warming FaSSIF to RT after refrigerating for $21 \mathrm{~h}$ does not restore the initial average particle size within the time frame studied.

\section{Influence of FaSSIF Particle Size on Dissolution}

The potential effect of slightly different particle sizes (in FaSSIF) on the dissolution of poorly water-soluble model drugs at $37^{\circ} \mathrm{C}$ was investigated (Figures $5 \mathrm{~A}, \mathrm{~B}$, and $\mathrm{C}$ ). Following the methods described below, FaSSIF media with two slightly different average particle sizes were produced by manipulating the hydration temperature:

1. FaSSIF with a $Z_{a v}$ of $30 \mathrm{~nm}$ was prepared by hydrating the powder at $37^{\circ} \mathrm{C}$ without equilibration for $2 \mathrm{~h}$.

2. FaSSIF with $Z_{\mathrm{av}}$ of $50 \mathrm{~nm}$ was prepared by hydrating at RT followed by the recommended 2 h equilibration.

The particle size of the media did not change during dissolution testing. The results of the dissolution with the three compounds are provided in the Figure below.

The figures show that the particle size did not influence the dissolution of the three compounds under the conditions tested. To compare the dissolution rates, the similarity factors $f_{2}$ were calculated (15). The dissolution curves related to phenytoin (A), dipyridamole (B), and ketoconazole $(C)$ show similarity factors of $71.0,75.5$, and 97.9 , respectively.

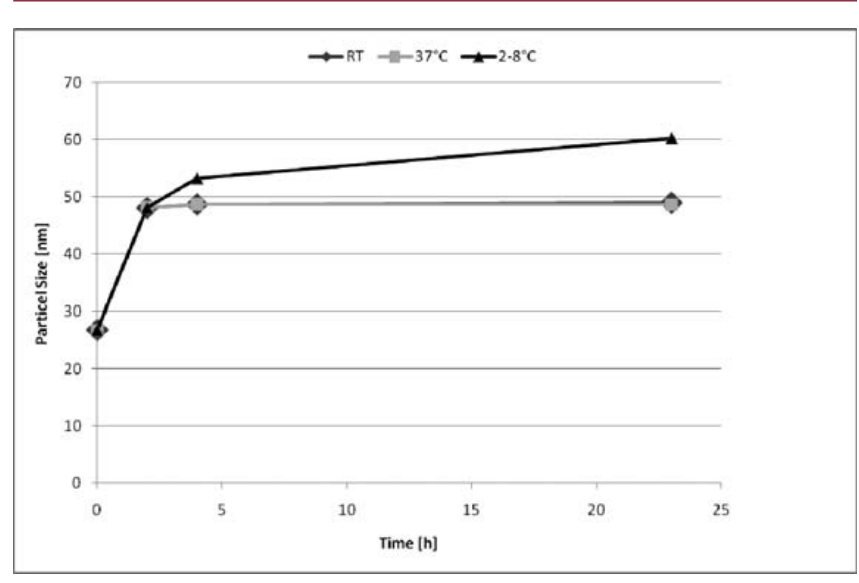

Figure 4. Influence of temperature on particle size FaSSIF measured with PCS $\left(2-8{ }^{\circ} \mathrm{C}, R T\right.$, and $\left.37^{\circ} \mathrm{C}\right)$, based on a single experiment.

\section{FeSSIF Particle Size}

The average particle size of FeSSIF prepared in triplicate from three independent batches of powder using the standard method was measured immediately after preparation and after $48 \mathrm{~h}$. The average particle size was $6.0 \mathrm{~nm}$ with a standard deviation of $0.1 \mathrm{~nm}$ immediately after preparation and after $48 \mathrm{~h}$. The average particle size also remained constant at $2-8^{\circ} \mathrm{C}$ and $37^{\circ} \mathrm{C}$ for $48 \mathrm{~h}$. An equilibration period for FeSSIF is, therefore, not required, and the hydration temperature does not affect the particle size.

Susceptibility of FaSSIF and FeSSIF to Microbial Spoilage

To establish the susceptibility to microbial growth, both FaSSIF and FeSSIF were subjected to the EP challenge test (Tables $3 \mathrm{~A}$ and $3 \mathrm{~B}$ ).

A log reduction $<1$ indicates that there was an increase in the number of microorganisms compared with $T_{0}$. FaSSIF was more susceptible to bacterial and fungal spoilage than FeSSIF.

\section{DISCUSSION}

A standardized homogeneous powder composed of taurocholate and lecithin presents a significant step forward for the convenient and rapid preparation of FeSSIF and FaSSIF. It employs the same composition as described by Marques (5) but avoids solvents (10).

\section{Storage of Powder}

The powder is physically and chemically stable for one year at $2-8{ }^{\circ} \mathrm{C}$. The inclusion of a desiccant inside the container prevents water uptake. Based on in-use experience (data not reported), the degree of oxidation of the lecithin in the opened container is very low even after frequent sampling.

\section{Practical Usage Tips}

To avoid condensation, the refrigerated powder should be allowed to reach RT before the container is opened. The exposure time should also be kept to a minimum. 


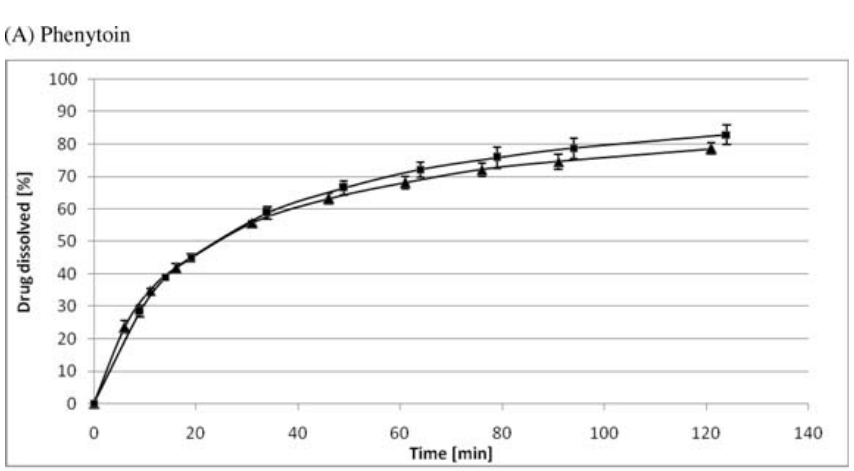

(B) Dipyridamole

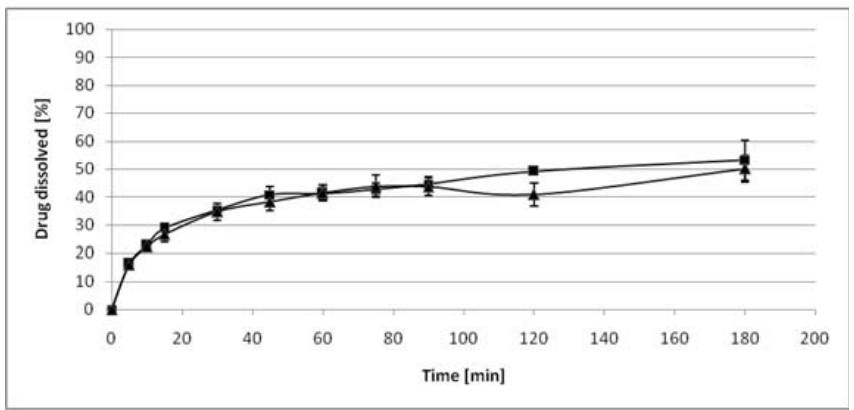

(C) Ketoconazole

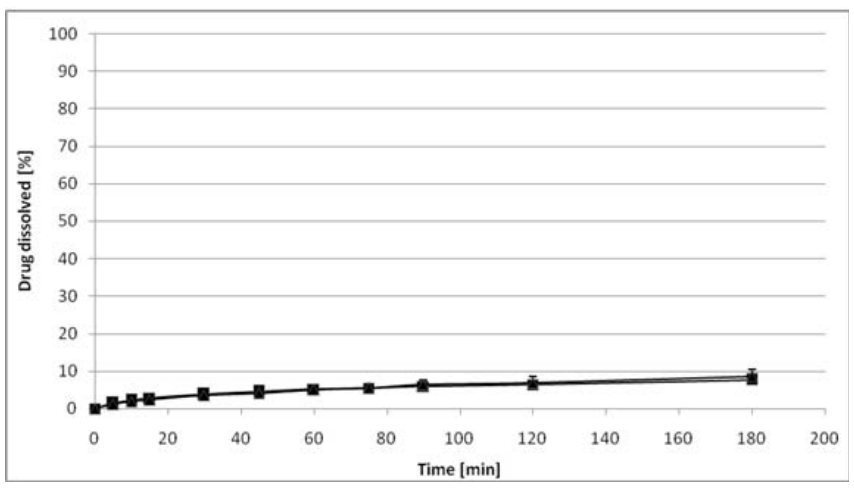

Figure 5. Influence of particle size of FaSSIF on the dissolution rate at $37^{\circ} \mathrm{C}$ of (A) dipyridamole, (B) ketoconazole, and (C) phenytoin; $\boldsymbol{\Delta}$ larger particles, - smaller particles.

\section{Chemical Characteristics}

No detectable lecithin hydrolysis (below LOD of $0.16 \%$ ) could be measured in either FaSSIF or FeSSIF after $24 \mathrm{~h}$ at $37^{\circ} \mathrm{C}$. UV spectroscopy revealed that there was a very low level of phospholipid oxidation in FeSSIF. In FaSSIF, oxidation was even lower, probably because the phospholipid concentration is five times lower. However, the more neutral $\mathrm{pH}$ and the buffer used for FaSSIF may also contribute. Regardless of the low level of oxidation in FeSSIF, the high molar extinction coefficient $\left(27,000 \mathrm{M}^{-1}\right.$ $\mathrm{cm}^{-1}$ ) of the peroxides formed (13) results in a high background UV signal, which may even increase during dissolution experiments. Since the mixed micelles possess a relatively high background UV signal, measurement of
Table 3. European Pharmacopoeia Antimicrobial Effectiveness Testing of FeSSIF (A) and FaSSIF (B) Expressed in Log Reduction of Microbial Content Compared to $\mathrm{T}_{0}$

\begin{tabular}{|c|c|c|c|c|}
\hline \multirow[t]{2}{*}{ Test microbe } & \multicolumn{4}{|c|}{ Incubation Period (Day) } \\
\hline & 2 & 7 & 14 & 28 \\
\hline \multicolumn{5}{|l|}{ (A) } \\
\hline $\begin{array}{l}\text { Staphylococcus } \\
\text { aureus }\end{array}$ & 1.1 & $>3.7$ & $>4.7$ & $>4.7$ \\
\hline $\begin{array}{l}\text { Pseudomonas } \\
\text { aeruginosa }\end{array}$ & $>3.7$ & $>4.7$ & $>4.7$ & $>4.7$ \\
\hline $\begin{array}{l}\text { Candida } \\
\text { albicans }\end{array}$ & NA & NA & $>1.1$ & $>4.1$ \\
\hline $\begin{array}{l}\text { Aspergillus } \\
\text { niger }\end{array}$ & NA & NA & $>1.5$ & $>3.5$ \\
\hline \multicolumn{5}{|l|}{ (B) } \\
\hline $\begin{array}{l}\text { Staphylococcus } \\
\text { aureus }\end{array}$ & $\begin{array}{c}0.1 \\
\text { (increase) }\end{array}$ & $\begin{array}{c}0.2 \\
\text { (increase) }\end{array}$ & $\begin{array}{c}0.5 \\
\text { (increase) }\end{array}$ & 2.0 \\
\hline $\begin{array}{l}\text { Pseudomonas } \\
\text { aeruginosa }\end{array}$ & $\begin{array}{c}0 \\
\text { (increase) }\end{array}$ & $\begin{array}{c}0 \\
\text { (increase) }\end{array}$ & $\begin{array}{c}0 \\
\text { (increase) }\end{array}$ & $\begin{array}{c}0 \\
\text { (increase) }\end{array}$ \\
\hline $\begin{array}{l}\text { Candida } \\
\text { albicans }\end{array}$ & nd & nd & $\begin{array}{c}0 \\
\text { (increase) }\end{array}$ & $\begin{array}{c}0.4 \\
\text { (increase) }\end{array}$ \\
\hline $\begin{array}{l}\text { Aspergillus } \\
\text { niger }\end{array}$ & nd & nd & $\begin{array}{c}0.4 \\
\text { (increase) }\end{array}$ & $\begin{array}{c}0.7 \\
\text { (increase) }\end{array}$ \\
\hline
\end{tabular}

drug dissolution/solubilization with UV spectroscopy below $280 \mathrm{~nm}$ may be problematic. For this reason, drug analysis in FeSSIF and FaSSIF is best performed using HPLC or UV equipment with special UV data analysis methods. In situations where a region of the UV spectrum of the drug lies above $280 \mathrm{~nm}$, this part of the spectrum may be used for quantification.

\section{Physical Characteristics}

The particle size and the type of colloidal micelles in mixed surfactant systems used as biorelevant media differ considerably compared with dissolution media containing micelles from single synthetic surfactants. FaSSIF contains an array of mixed micelles such as spherical, rod-like, disk, and bilayer micelles and liposomal structures. In contrast, FeSSIF mainly comprises smaller mixed micelles.

It is important to control the molar ratio of lecithin and cholate within well-defined limits to obtain consistent particle size and solubilization characteristics, which is why the QC specifications of the powder are narrowly set. Control is important because lecithin on its own forms liposomes when hydrated, whereas sodium taurocholate above its CMC (Critical Micelle Concentration) forms micelles. By using analytical quality components and even accounting for the water content of the raw materials before manufacture, the amount of taurocholate and 
lecithin is narrowly controlled in a 4:1 molar ratio for every batch of powder.

The phase diagram of lecithin/water/taurocholate is detailed in the literature $(17,18)$. However, the exact phase diagrams of FeSSIF and FaSSIF are not described, because these media have different $\mathrm{pH}$ and salt compositions. The type of mixed micelle formed is determined by the molar ratio of the components, taurocholate concentration, $\mathrm{pH}$ salt strength, and temperature. At a high taurocholate concentration, predominantly smaller micelle aggregates are formed, whereas at a lower concentration, there is a tendency to form larger micelles and eventually liposomes, because phospholipid molecules intrinsically rearrange into bilayered aggregates (19). The minimum concentration at which the surfactant starts to form micelles from single molecules (CMC) will also be important in the formation of mixed micelles with lecithin. From the literature, it appears that the taurocholate CMC lies in a broad range between 1 and $12 \mathrm{mM}(20)$. There is also debate on whether taurocholate has a CMC at all and whether increasing the concentration forms aggregates that gradually increase in size $(20,21)$. FaSSIF has a taurocholate concentration of $3.75 \mathrm{mM}$, which means (irrespective of whether or not there is a CMC) that the taurocholate has a very low tendency to self-associate (unlike phospholipids). Larger structures such as disk-like micelles and even liposomes are present (see Figure 3). After equilibration, the $Z_{a v}$ is between 30 and $70 \mathrm{~nm}$ for FaSSIF. This finding agrees with the structures found in natural bile $(18,22)$. Visually, FaSSIF is clear to slightly opalescent. This medium is generally slightly opalescent above an average size of approximately $50 \mathrm{~nm}$ and is clear below approximately $50 \mathrm{~nm}$. Furthermore, judging the appearance can be subjective; larger volumes of FaSSIF appear more opalescent than smaller volumes. Thus, only a very small difference in average particle size may influence the visual appearance of FaSSIF.

\section{Equilibrium}

To prepare FaSSIF with a consistent size, it should be equilibrated for two hours at RT after dissolving the powder. This agrees with the kinetics related to the transition and growth of lipid particles from initial true (smaller) mixed micelles to disk-like (larger) structures, which take hours (23). The transition process is induced by the dilution of a more concentrated mixed micellar mixture towards the CMC region of the detergents. It is also common practice for physicists to equilibrate mixed micelles before studying their properties $(18,24)$.

The equilibrium of the aggregates in FaSSIF and the corresponding average size is influenced by temperature. Refrigerating FaSSIF increases the particle size, which is not reversible even upon warming to $\mathrm{RT}$, possibly because the larger structures may be kinetically favored. The lack of influence of heating at $37^{\circ} \mathrm{C}$ may be explained by the greater physical stability of the larger particles formed after reaching equilibrium at RT (Figure 4).

\section{Dissolution}

The dissolution of the three poorly water-soluble compounds in two FaSSIF media with an average particle size controlled at less than $30 \mathrm{~nm}$ and greater than $50 \mathrm{~nm}$ was compared. Particle size did not influence the dissolution rate. However, it cannot be entirely ruled out that the dissolution rate of some compounds will not be affected by a difference in particle size caused by a shift in ratio from smaller to larger mixed micelles. To ensure consistency, FaSSIF can be prepared using the procedure described in the Methods section to produce consistent media. For practicality and reproducibility, preparation at room temperature is recommended. The particle size of FeSSIF is not influenced by temperature changes in the range of $0-37^{\circ} \mathrm{C}$, and equilibration is not needed.

\section{Microbial Susceptibility}

FaSSIF is more susceptible to spoilage than FeSSIF. FaSSIF is less hostile toward microbes, possibly due to a more neutral $\mathrm{pH}$ and lower taurocholate concentration, which does not disrupt microbial membranes. To minimize spoilage, FaSSIF should be used within $48 \mathrm{~h}$ at RT or $24 \mathrm{~h}$ at $37^{\circ} \mathrm{C}$ after preparation. Although the microorganisms challenged in FeSSIF did not cause spoilage in the short time period tested, other types of microorganisms may grow.

\section{CONCLUSION}

The taurocholate-lecithin powder is stable in its primary glass container for at least one year at refrigerated conditions.

Both media are stable to hydrolysis for $48 \mathrm{~h}$. Although the level of phospholipid oxidation detectable over $48 \mathrm{~h}$ is very low, it may interfere with UV measurements below about $280 \mathrm{~nm}$. Electron microscopy revealed the presence of a mixture of lipid structures in FaSSIF. Controlling the temperature and equilibrating for $2 \mathrm{~h}$ after preparation produces FaSSIF reproducibly with a consistent and narrow particle size range. FeSSIF contained only (smaller) mixed micelles that were not influenced by time and temperature.

FaSSIF is more susceptible to microbial spoilage and should be prepared and used within $48 \mathrm{~h}$. In contrast, the challenge test microorganisms did not cause significant spoilage of FeSSIF.

Dissolution of the three poorly soluble compounds studied was not significantly different in FaSSIF media having two slightly different particle sizes. However, it cannot be ruled out that the dissolution of some compounds or formulations is not influenced by particle size.

FeSSIF and FaSSIF can be conveniently produced from the powder in a reproducible manner by following standard preparation methods and storage conditions.

\section{REFERENCES}

1. Galia, E.; Nicolaides, E.; Hörter, D.; Löbenberg, R.; Reppas, C.; Dressman, J. B. Evaluation of various 
dissolution media for predicting in vivo performance of Class I and II drugs. Pharm. Res. 1998, 15, 698-705.

2. Dressman, J. B.; Thelen, K.; Jantratid, E. Towards quantitative prediction of oral drug absorption. Clin. Pharmacokinet. 2008, 47, 655-667.

3. Dressman, J. B.; Vertzoni, M.; Goumas, K.; Reppas, C. Estimating drug solubility in the gastrointestinal tract. Adv. Drug Deliver. Rev. 2007, 59, 591-602.

4. Kuentz, M. Drug Absorption Modeling as a Tool to Define the Strategy in Clinical Formulation Development, Towards Integrated ADME Prediction: Past, Present, and Future. AAPS J. 2008, 10 (3), 473-479.

5. Marques, M. Dissolution media simulating fasted and fed states. Dissolution Technol. 2004, 11 (2), 16.

6. Ilardia-Arana, D.; Kristensen, H. G.; Müllertz, A. Biorelevant dissolution media: aggregation of amphiphiles and solubility of estradiol.J.Pharm. Sci. 2006, 95 (2), 248-255.

7. Vertzoni, M.; Fotaki, N.; Kostewicz, E.; Stippler, E.; Leuner, C.; Nicolaides, E.; Dressman, J.; Peppas, C. Dissolution media simulating the intraluminal composition of the small intestine: physiological issues and practical aspects. J. Pharm. Pharmacol. 2004, 56, 453-462.

8. Jantratid, E.; Dressman, J. Biorelevant dissolution media simulating the proximal human gastrointestinal tract: an update. Dissolution Technol. 2009, 16 (3), 21-25.

9. Leigh, S.; Leigh, M. L. S.; van Hoogevest, P.; Streich, D.; Quinton, J. Dissolution composition for examining drug solubility. Eur. Pat. Appl. 1952142, 2006.

10. Boni, J. E.; Brickl, R. S.; Dressman, J. B.; Pfefferle, M. L. Instant FaSSIF and FeSSIF-Biorelevance Meets Practicality. Dissolution Technol. 2009, 16 (3), 41-46.

11. Rossi, S. S.; Converse, J. L.; Hofmann, A. F. High pressure liquid chromatographic analysis of conjugated bile acids in human bile: simultaneous resolution of sulfated and unsulfated lithocholyl amidates and the common conjugated bile acids. J. Lipid Res. 1987, 28, 589-595.

12. New, R. R. C. Characterization of Liposomes. In Liposomes: A Practical Approach; Rickwood, D., Hames, B. D., Eds.; Oxford University Press: New York, 1990; p 116.

13. Kim, R. S.; La Bella, F. S. Comparison of analytical methods for monitoring auto-oxidation profiles of authentic lipids. J. Lipid Res. 1987, 28, 1110-1117.
14. 5.1.3 Efficacy of Antimicrobial Preservation. In European Pharmacopoeia, 6th ed.; European Directorate for the Quality of Medicines, Council of Europe: Strasbourg, France, 2007.

15. Dissolution Testing of Immediate Release Solid Oral Dosage Forms; Guidance for Industry; U.S. Department of Health and Human Services, Food and Drug Administration, U.S. Government Printing Office: Washington, DC, 1997.

16. Samumi, A. M.; Lipman, A.; Barenholz, Y. Damage to liposomal lipids: protection by antioxidants and cholesterol-mediated dehydration. Chem. Phys. Lipids 2000, 105, 121-134.

17. Shankland, W. The equilibrium and structure of lecithin-cholate mixed micelles. Chem. Phys. Lipids 1970, 4, 109-130.

18. Cohen, D. E.; Thurston, G. M.; Chamberlin, R. A.; Benedek, G. E; Carey, M. E. Laser light scattering evidence for a common wormlike growth structure of mixed micelles in bile salt- and strain-chain detergentphosphatidylcholine aqueous systems: relevance to the micellar structure of bile. Biochemistry 1998, 37, 14798-14814.

19. Egelhaaf, S. U.; Schnurtenberger, P. Micelle-to-vesicle transition. A time-resolved structural study. Phys. Rev. Lett. 1999, 82, 2804-2807.

20. Carey, M.C. Measurement of the physical-chemical properties of bile salt solutions. In Bile Acids in Gastroenterology; Barbara, L., Dowling, R. H., Hofmann, A. F., Roda, E., Eds.; MTP Press: Lancaster, England, 1983; pp 19-56.

21. Spivak, W.; Morrison, C.; Devinuto, D.; Yuey, W. Spectrophotometric determination of the critical micellar concentration of bile salts using bilirubin monoglucuronide as a micellar probe. Biochem.J. $1988,252,275-281$.

22. Cohen, D. E.; Angelico, M.; Carey, M. C. Quasielectric scattering evidence for vesicular excretion of biliary lipids. Am. J. Physiol. - Gastr. L. 1989, 257, 1-8.

23. Leng, J.; Egelhaaf, S. U.; Cates, M. E. Kinetics of the micelle-to-vesicle transition: aqueous lecithin-bile salt mixtures. Biophys. J. 2003, 85, 1624-1646.

24. Mazer, N. A.; Benedek, G. A.; Carey, M. C. Quasielectric light scattering studies of aqueous biliary lipid systems. Mixed micelles formation in bile salt-lecithin solution. Biochemistry 1980, 19,601-615. 